\title{
Step-wise relocation of ISC earthquake hypocenters for linearized tomographic imaging of slab structure
}

\author{
R.D. van der Hilst ${ }^{a}$ and E.R. Engdahl ${ }^{b}$ \\ ${ }^{a}$ Department of Earth Sciences, the University of Leeds, Leeds, LS2 9JT, UK \\ ${ }^{\mathrm{b}}$ U.S.G.S., National Earthquake Information Center, MS 967, Box 25046, DFC, Denver, CO 80225, USA
}

(Received 7 February 1992; accepted 1 July 1992)

\begin{abstract}
Van der Hilst, R.D. and Engdahl, E.R., 1992. Step-wise relocation of ISC earthquake hypocenters for linearized tomographic imaging of slab structure. Phys. Earth Planet. Inter., 75: 39-53.

A vast volume of seismic phase data, computed from routinely determined hypocenter locations, is presently available for seismic imaging techniques such as tomographic inversion and residual sphere analysis. Routinely reported earthquake hypocenters, however, can be in error by several tens of kilometers. These biases in hypocenter location can result in the misidentification of seismic phases and the loss of structural signal in the seismic phase data. Thus, the value of these data in constraining seismic images is significantly reduced. Furthermore, hypocenter mislocations degrade the linearization of the tomographic problem and map into the images produced by tomographic inversion.

To obtain adequate reference hypocenters for linearized inversion, we used iasp91 software and reported arrival times to reprocess ISC hypocenters and phase data for northwest Pacific earthquakes. Subsequently, we inverted P- and pP-wave residuals for Earth structure and source (mis)location. We describe this step-wise relocation of ISC hypocenters, which underlies the linearization of the tomographic inversion, and compare the relocation vectors before and after inversion.

The hypocenter relocations determined prior to inversion are of the order of $10 \mathrm{~km}$, which is significant with regard to both the estimated standard errors and the effect on travel-time residuals, and systematic with regard to earthquake position in the subducted slab. In contrast, the spatial components of the relocation vectors determined upon inversion of $\mathrm{P}$ and $\mathrm{pP}$ residuals are up to an order of magnitude smaller, do not reveal a correlation with location in the seismic zone, and do not generally exceed the noise level.

The incorporation of $\mathrm{pP}$ data in the relocation was essential to remove the depth bias prior to inversion, to retrieve slab signal that might have been absorbed in mislocation, and to constrain the focal depth upon seismic inversion. Non-linear inversion schemes will not be efficient in removing the depth bias or in retrieving lost slab signal unless seismic phases that contain additional information about the depth bias, like the depth phase pP, are used.
\end{abstract}

\section{Introduction}

The success of many seismological studies depends on both the accuracy of earthquake hypocenters and the quality of travel times (or travel-time residuals) of associated seismic phases published by international agencies such as the International Seismological Centre (ISC) and the

Correspondence to: R.D. van der Hilst, Research School of Earth Sciences, Australian National University, G.P.O. Box 4, Canberra, A.C.T. 2601, Australia.
National Earthquake Information Center (NEIC). In this paper we focus on the hypocenters and seismic data from earthquakes of focal depth greater than $70 \mathrm{~km}$. They are of particular interest (cf. Frohlich, 1989) because they: (1) occur in large numbers; (2) are associated with subduction zones; (3) produce higher-quality phase data; (4) have an interesting physical nature (Burnley and Green, 1991; Helffrich and Brodholt, 1991; Kirby et al., 1991); (5) are prone to mislocation.

For the determination of hypocentral parameters the ISC uses a standard least-squares proce- 
dure based on Jeffreys' method of uniform reduction (Jeffreys, 1939; Bolt, 1960; Buland, 1976, 1986) and P-wave travel-time tables derived from a radially stratified Jeffreys-Bullen (JB) Earth model (Jeffreys and Bullen, 1967; Adams et al., 1982). The associated phase data and residuals resulting from this hypocenter determination are routinely reported by the ISC. Any errors in the JB tables (e.g. due to unknown Earth structure) are mapped into biases in the estimated hypocentral parameters (Adams et al., 1982; Buland, 1986). Almost all deep-focus earthquakes occur in or near subducted lithosphere where aspherical variations in propagation velocity of seismic waves are large, i.e. of the order of $5-10 \%$ (Engdahl, 1973). Such lateral variations in seismic velocity, the uneven spatial distribution of seismological stations, and the specific choice of seismic data used to determine the earthquake hypocenter, can easily combine to produce earthquake mislocations of several tens of kilometers (Engdahl et al., 1977, 1982; Dziewonski and Anderson, 1983; Nieman et al., 1986) and the misidentification of seismic phases (Engdahl and Van der Hilst, 1991). If, for instance, the P-wave data used for the location of a subduction zone earthquake are mainly from stations at large epicentral distances, the focal depth can be overestimated and slab effects on the travel times can be lost from the published P residual data (Fig. 1(a)).

When the distribution of hypocenters, aligned along seismic Wadati-Benioff zones, is used to delineate large-scale slab structure (e.g. Isacks and Barazangi, 1977; Billington, 1980; Burbach and Frohlich, 1986; Chiu et al., 1991), location errors of the order of $10 \mathrm{~km}$ are not always significant. However, the use of inaccurate hypocenter locations can prohibit the detailed investigation of relationships between seismicity and slab structure, e.g. double Wadati-Benioff zones (Engdahl and Scholz, 1977; Hasegawa et al., 1978a, b; Ishida and Hasemi, 1988). Because of the danger of structural signal being mapped into biased hypocentral parameters, large mislocations may have a significant effect on investigations where both the locations and travel times of seismic waves from deep earthquakes are used. Examples include studies of the physical mechanism of deep-focus earthquakes (Iidaka and Suetsugu, 1990, 1992; Helffrich and Brodholt, 1991), investigations of subduction zone morphology with seismic imaging techniques such as bodywave tomography (for northwest Pacific slab structure: Hirahara and Mikumo, 1980; Nakanishi, 1985; Kamiya et al., 1988; Suetsugu, 1989; Spakman et al., 1989; Zhou and Clayton, 1990;

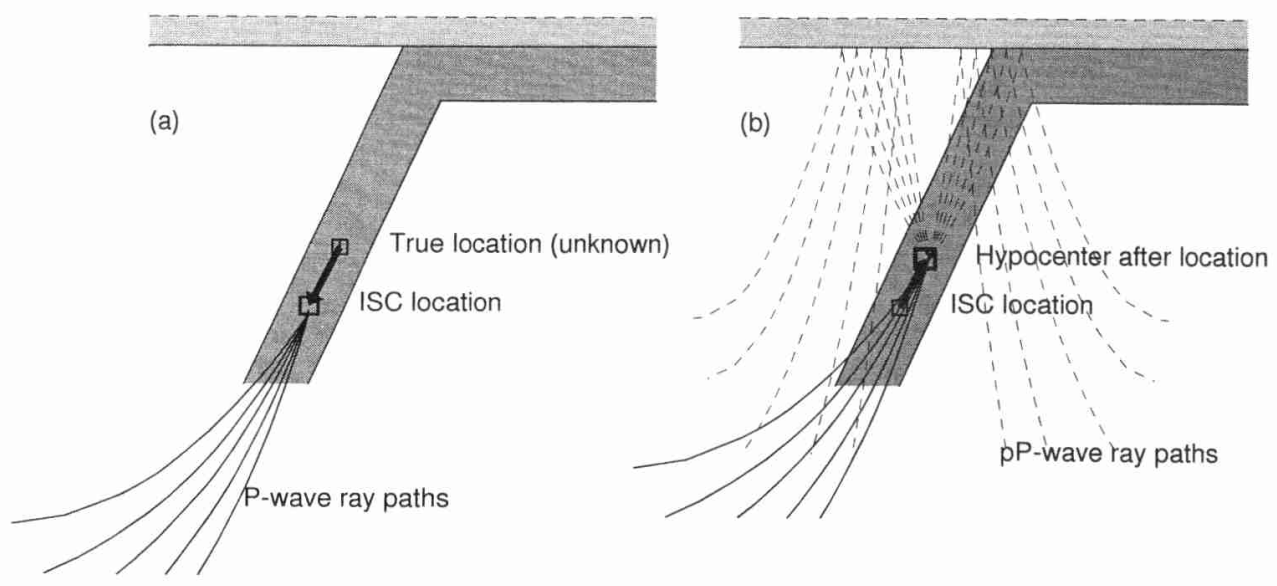

Fig. 1. Schematic diagram illustrating the effect on hypocenter relocation of the incorporation of pP phase data. (a) Overestimation of focal depth of a subduction zone earthquake in the case where only P-wave data from stations at large epicentral distances are used for location. (b) The reflection points of pP add, in effect, local sources and receivers (Engdahl and Billington, 1986; Engdahl and Gubbins, 1987). 
Hasegawa et al., 1991; Van der Hilst et al., 1991, 1992; Fukao et al., 1992) and residual sphere analyses (e.g. Jordan, 1977; Creager and Jordan, 1984, 1986; Fischer et al., 1991). The use of routinely determined ISC hypocenter determinations for tomographic imaging and residual sphere analyses is of particular interest for this paper.

In tomographic imaging and residual sphere analyses it is usually assumed that for some reference Earth model the earthquakes are well located and mislocations are due to structure not accounted for in that model. If source mislocation is small, the problem of hypocenter location can be linearized successfully about a trial solution, i.e. the source location in the reference model (e.g. Buland, 1976; Aki and Richards, 1980). This is part of the linearization of the tomographic problem. Application in an inversion scheme is straightforward (Spencer and Gubbins, 1980; Spakman and Nolet, 1988; Inoue et al., 1990), but there is a real danger that biases in hypocenter determinations map into the results of the tomographic inversions. In contrast, small earthquake mislocations do not bias the result of residual sphere analyses because the effect of earthquake mislocation can be projected outside the model space (Jordan, 1977; Creager and Jordan, 1984). However, structural signal lost in source mislocation cannot be exploited to constrain the images by either method.

We argue that biases in hypocenter determinations can be significantly reduced, and at least part of the lost structural signal retrieved, by explicitly relocating the hypocenters of subduction zone earthquakes in the new iasp91 reference model (Kennett, 1991; Kennett and Engdahl, 1991). In particular, to constrain the focal depth of an earthquake we use data of the depth phase $\mathrm{pP}$ in addition to the first-arriving P-phase (Fig. 1(b)). We note that also the ISC reports focal depths based on $\mathrm{pP}-\mathrm{P}$ differential travel times for a substantial number of events; the travel-time residuals published in the 'Bulletins of the International Seismological Centre' are, however, computed predominantly from hypocenters located with P-wave travel times only (Adams et al., 1982; Adams, personal communication, 1991). For a detailed discussion of hypocenter relocation prior to inversion for aspherical Earth structure, we refer the reader to Engdahl and Van der Hilst (1991). With reprocessed hypocenters and phase data we find that tomographic inversion yields more reliable images of 3-D Earth structure. Results of the application of our earthquake relocation approach to a tomographic study of northwest Pacific slab structure are published elsewhere (Van der Hilst et al., 1991, 1992). The objectives of the present paper are to describe briefly the step-wise relocation of ISC hypocenters that underlies our linearized tomographic imaging and to stress the importance of incorporating $\mathrm{pP}$ data in earthquake (re)location. We compare the length and direction of hypocenter relocation vectors before and after tomographic inversion. We focus our attention on deep earthquakes (depth greater than $70 \mathrm{~km}$ ) in the major seismic zones below northwest Pacific island arcs.

\section{Method}

In our tomographic inversions we use $\mathrm{pP}$-wave data as well as P-wave data, because $\mathrm{pP}$ waves sample shallow Earth structure more effectively than $\mathrm{P}$ waves, and because the combined use of $\mathrm{P}$ - and $\mathrm{pP}$-wave arrival times puts strong constraints on the earthquake focal depth (Aki and Richards, 1980; Engdahl and Billington, 1986; Engdahl and Gubbins, 1987; Van der Hilst and Engdahl, 1991). ISC hypocenters computed using only first-arriving, P-wave arrival times have, in most cases, poorly resolved focal depths.

Data of seismic phases other than $\mathrm{P}$ are not necessarily consistent with the ISC hypocenter determinations. In the example of Fig. 1(a), pPwave travel-time residuals computed from an overestimated focal depth will have a substantial negative bias (Van der Hilst and Engdahl, 1991). To remove this bias, ISC hypocenters below northwest Pacific island arcs were relocated using the iasp91 reference Earth model (Kennett and Engdahl, 1991), all seismic phases reidentified, and new travel-time residuals computed. Resulting $\mathrm{P}$ - and $\mathrm{pP}$-wave travel-time residuals were then used to invert for source relocation and aspherical variations in P-wave velocity. The gen- 
eral objective of relocating earthquakes before inversion for aspherical Earth structure is to satisfy requirements for the linearization of the tomographic problem. Inaccuracies in the $\mathrm{JB}$ travel-time tables for $\mathrm{P}$ waves produce a bias in the hypocentral parameters published by the ISC, which can be of the same order of magnitude as the standard errors in these parameters (Adams et al., 1982). Specifically, we aim to remove this bias and to reduce the effect of unknown slab structure on focal depth estimates.

\subsection{Hypocenter location and seismic phase associ- ation in iasp 91 before inversion}

A major international effort within the International Association of Seismology and Physics of the Earth's Interior (IASPEI) over the last 3 years has led to the construction of a new global travel-time model (iasp91) to replace the JB tables for earthquake location and phase identification (Kennett, 1991; Kennett and Engdahl, 1991). This new radially stratified model has been constructed so that the travel times for the major seismic phases are consistent with the observations for events in the 'Bulletin of the International Seismological Centre' for the period 19641987. The primary form of representation of the travel times that can be derived from the iasp91 model is based on a set of algorithms (Buland and Chapman, 1983) that provide rapid calculations of the travel times of an arbitrary set of phases for a specified source depth and epicentral distance. Van der Hilst et al. (1991, 1992) have shown that the variance of $\mathrm{P}$ residuals resulting from hypocenter location with the iasp91 travel-time tables is $17 \%$ less than the variance of reported ISC P residuals, which are computed with the JB tables. This difference in data variance, which is mainly due to differences in iasp91 and $\mathrm{JB}$ travel-time tables, is of the same order of magnitude as the variance reductions typically obtained by tomographic inversion of ISC $\mathrm{P}$ residuals. As the data set used in this paper is identical to that of the earlier study, we only briefly describe below the relocation procedure they used.
Because of the major differences between the iasp91 and JB travel times, a starting premise for the relocation is that all phase identifications reported by the ISC will require reidentification. This is accomplished by a two-step processing procedure, using ISC starting locations and reported arrival times (Engdahl and Van der Hilst, 1991). The first step involves a sequence of fixed depth iterative solutions using only first-arriving, P-wave arrival times. New phase identifications are made after each iteration. The procedure begins with a time window of $[-15.0,+15.0]$ seconds for association of usable phase arrival times. This time window is successively reduced after each solution to a final set of windows based on the statistical properties of the phases being associated $([-4.5,+4.5]$ seconds for residuals of later phases and $\mathrm{P}$ waves at regional distances, and $[-3.5,+3.5]$ seconds for $P$ residuals at teleseismic distances). Arrivals falling within the predicted intersection of the time windows for crossing phases constitute unknown phase associations and these data undergo no further processing. The second step is an iterative procedure to constrain focal depth by using both $\mathrm{P}$ - and pPwave arrival times falling within fixed time windows for phase association as defined above. If the focal depth determined by this procedure is poorly resolved, the depth is fixed at its starting value (but, if necessary, seismic phases are reidentified). If the statistical error vector of the final solution is greater than $25 \mathrm{~km}$, the event is rejected. Since earthquakes are located by computing corrections to some starting hypocenter, this processing approach ensures that an ISC starting hypocenter will not unduly influence the final result and that local minima in the solution space are avoided.

In the free-depth solutions the focal depth is largely controlled by regional P-wave arrivals and later phases which have been identified as $\mathrm{pP}$ (Fig. 1(b)). Although the phase association criteria used in the relocation successfully separate $\mathrm{PcP}$ and $\mathrm{sP}$ phases from the $\mathrm{pP}$ phase at depths greater than $35 \mathrm{~km}$, it does not account for any pwP phases that may be present for epicenters beneath oceanic regions. By examining $\mathrm{pP}$ residuals from deeper events as a function of bounce- 
point water depth, Engdahl and Van der Hilst (1991) are able to confirm that many later arrivals with large positive residuals that had been identified as pP were actually pwP phases. Since the pwP residuals are ordinarily large and inconsistent with depths constrained by $\mathrm{P}$ arrivals from nearby stations, most pwP arrivals are automatically removed from the solution.

For fixed- or free-depth solutions less than 35 $\mathrm{km}$ in focal depth, phase association is accomplished by using the smallest absolute residual rather than time windows. This is not very satisfactory, but most of the depth phases would be eliminated otherwise. However, the procedure does not seem to result in any serious problems. The depth phases appear to get properly associated and the focal depth determination of shallow events is considerably enhanced. Moreover, the $\mathrm{pP}$ residuals from these events will not be used in the tomographic inversion as the path separation from $\mathrm{P}$ is too small to give any new information about structure.

\subsection{Inversion for source location and 3-D Earth structure}

In our tomographic study, we interpret the P and $\mathrm{pP}$ residuals obtained from the procedure described above in terms of perturbations to the iasp91 reference model and to the trial hypocenter parameters. The theoretical travel-time $T_{i j}$ between the $i$ th seismic event and the $j$ th receiving station can be written as (Spencer and Gubbins, 1980)

$$
T_{i j}=\int_{L_{i j}(3-\mathrm{D})} S \mathrm{~d} l
$$

where the slowness field $S(\boldsymbol{r})$ is integrated along the ray path $L_{i j}(3-D)$. Equation (1) is non-linear, because the integration path $L_{i j}(3-\mathrm{D})$ depends on the (unknown) location of the earthquake and the 3-D Earth structure we aim to solve for. It is well known that, with the following assumptions, eqn. (1) can be linearized about the reference velocity model and source locations (e.g. Bolt, 1960; Buland, 1976; Aki and Richards, 1980; Spakman, 1988). First, we assume that the reference Earth model is sufficiently close to the true Earth so that we can apply Fermat's principle, which states that the arrival time is stationary with respect to the perturbation of the ray path about the true path. Second, we assume for each earthquake that the trial solution for hypocenter location $\hat{\boldsymbol{x}}_{0}$, as determined prior to inversion (see Section 2.1), is sufficiently close to the true location $\boldsymbol{x}_{0}$ so that the change in travel time of a seismic wave from source to station, due to a small perturbation in the hypocentral parameters, is virtually unchanged between $\hat{\boldsymbol{x}}_{0}$ and $\boldsymbol{x}_{0}$ (Aki and Richards, 1980). The travel-time residual $\delta T$, the difference between the observed arrival time and the time predicted from the reference model, can then be written as the contribution of Earth structure not accounted for in the reference model and the effect of a small mislocation $\Delta x_{0}$ due to the presence of this unknown structure:

$$
\begin{aligned}
\delta T_{i j}= & \left(T_{\text {observed }}-T_{0}\right)_{i j} \\
= & \int_{L_{i j}(0)} \Delta S \mathrm{~d} l+\left(\frac{\partial T_{i j}}{\partial h_{i}}\right) \delta h_{i}+\left(\frac{\partial T_{i j}}{\partial \theta_{i}}\right) \delta \theta_{i} \\
& +\left(\frac{\partial T_{i j}}{\partial \phi_{i}}\right) \delta \phi_{i}+\delta t_{0, i}+\epsilon
\end{aligned}
$$

or

$$
\delta T_{i j}=\int_{L_{i j}(0)} \Delta S \mathrm{~d} l+\sum_{k=1}^{4} \frac{\partial T_{i j}}{\partial x_{i k}} \delta x_{i k}+\epsilon
$$

where $\Delta S$ is the slowness perturbation relative to the reference slowness field; $\left(h, \theta, \phi, t_{0}\right)_{i}=\hat{x}_{0, i}$ the $i$ th reference hypocenter (focal depth, longitude, latitude, origin time) and $\left(\delta h, \delta \theta, \delta \phi, \delta t_{0}\right)_{i}$ $=\Delta x_{0, i}$ the perturbation to $\hat{x}_{0, i}$; and $\partial T_{i j} / \partial x_{i k}$ $(k=1,2,3,4)$ the hypocenter partial derivatives which can be computed if the ray parameter is known, e.g. from the travel-time tables. In (2), $\epsilon$ represents second-order terms in the linearization, which will be neglected. The integration path $L_{i j}(0)$ is now computed in the reference Earth model. The slowness part in (2) is parameterized with slowness functions represented by non-overlapping cells, in each of which the slowness is taken as constant (Nolet, 1985; Spakman and Nolet, 1988). The integral of the slowness perturbation along the reference ray path (2) is 
then replaced by a summation over the slowness perturbation multiplied by the path length of a ray in a particular cell. This is not shown here as we are primarily interested in the mislocation part.

From (2) it follows that the relocation of each earthquake involves the determination of four unknowns in $\Delta x_{0}$. In our tomographic study we used about 45000 earthquakes, which would thus amount to 180000 unknowns for source location; the parameterization of the velocity part of (2) involves about 50000 unknowns (Van der Hilst et al., 1992). To reduce the number of unknowns in the hypocenter relocation we assume that $\Delta x_{0}$ is the same for earthquakes that are spatially close together. Following Spakman and Nolet (1988), we group the earthquakes within a particular mantle volume (e.g. with dimensions of $0.5^{\circ} \times 0.5^{\circ}$ $\times 50 \mathrm{~km}$ ) into a cluster. We then determine hypocenter partial derivatives and, consequently, $\Delta \boldsymbol{x}_{0}$ for clusters of earthquakes (Spakman and Nolet, 1988). This reduces the number of unknowns for hypocenter relocation to nearly 70000 (Van der Hilst et al., 1992). In our study we used about $1000000 \mathrm{P}$ - and $100000 \mathrm{pP}$-wave traveltime residuals to solve for effects of mislocation

\section{Kuril region: epicenter mislocation}

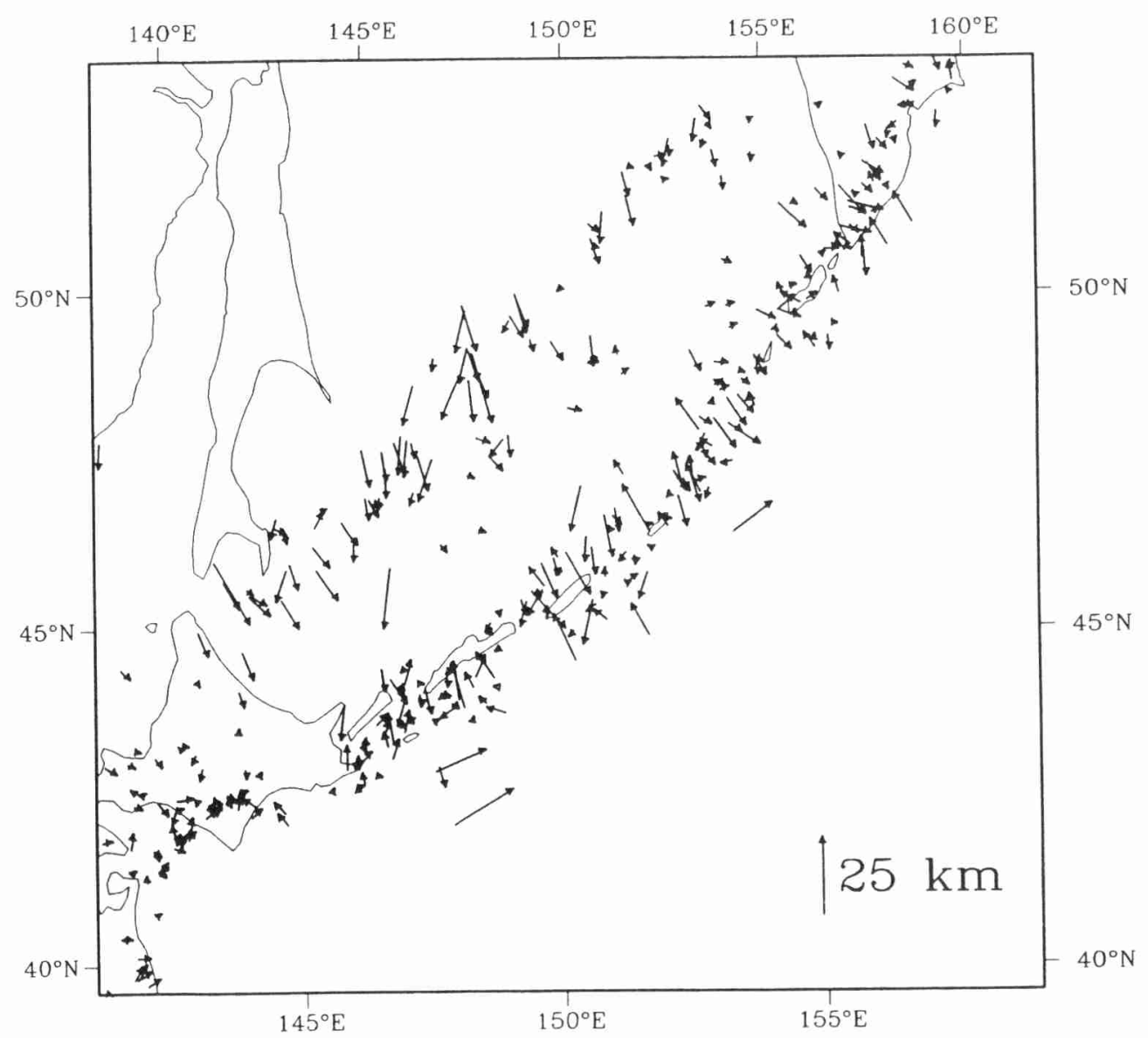

Fig. 2. Epicenter relocation vectors for intermediate and deep earthquakes in the Kuril region as determined prior to inversion for 3-D Earth structure (after Engdahl and Van der Hilst, 1992, in preparation). The tail of the arrows depict the ISC epicenter locations that were used as starting values; the head of the arrows mark the epicenter locations obtained with iasp91 software and the combination of $\mathrm{P}$ - and $\mathrm{pP}$-wave travel-time residuals. 
and for slowness perturbations to iasp91 using the LSQR algorithm of Paige and Saunders (1982) (Nolet, 1985; Spakman and Nolet, 1988).

We remark that the hypocenter relocation upon inversion differs in a fundamental way from that described in Section 2.1. Initially, the objective of relocation is to find the best hypocentral parameters in a spherically symmetric reference model. In the tomographic imaging, however, the effort to locate earthquakes is effectively subordinate to the problem of determining model parameters for 3-D Earth structure. In addition, the reprocessing of ISC hypocenters was performed for individual earthquakes, whereas, upon subsequent inversion for aspherical Earth structure, the relocation parameters are computed for clusters of events.
In the inversion, there is a direct trade-off between the amplitudes of imaged variations in slowness and the size of the relocation vector $\Delta \boldsymbol{x}_{0}$. This trade-off can be controlled during the inversion by weighting the contribution to $\delta T_{i j}$ of lateral heterogeneity and hypocenter relocation, but the choice of the weighting factors is somewhat subjective (Spakman and Nolet, 1988). Formally, $\Delta \boldsymbol{x}_{0}$ can be computed, but the relocation vector is not well constrained and is commonly not used to update the hypocentral parameters explicitly. An exception to the latter is the iterative relocation underlying the tomographic inversion of Fukao et al. (1992). Instead, we exploit only the effect of relocation on travel time in the tomographic inversions. If necessary, final hypocenter locations can be found with more

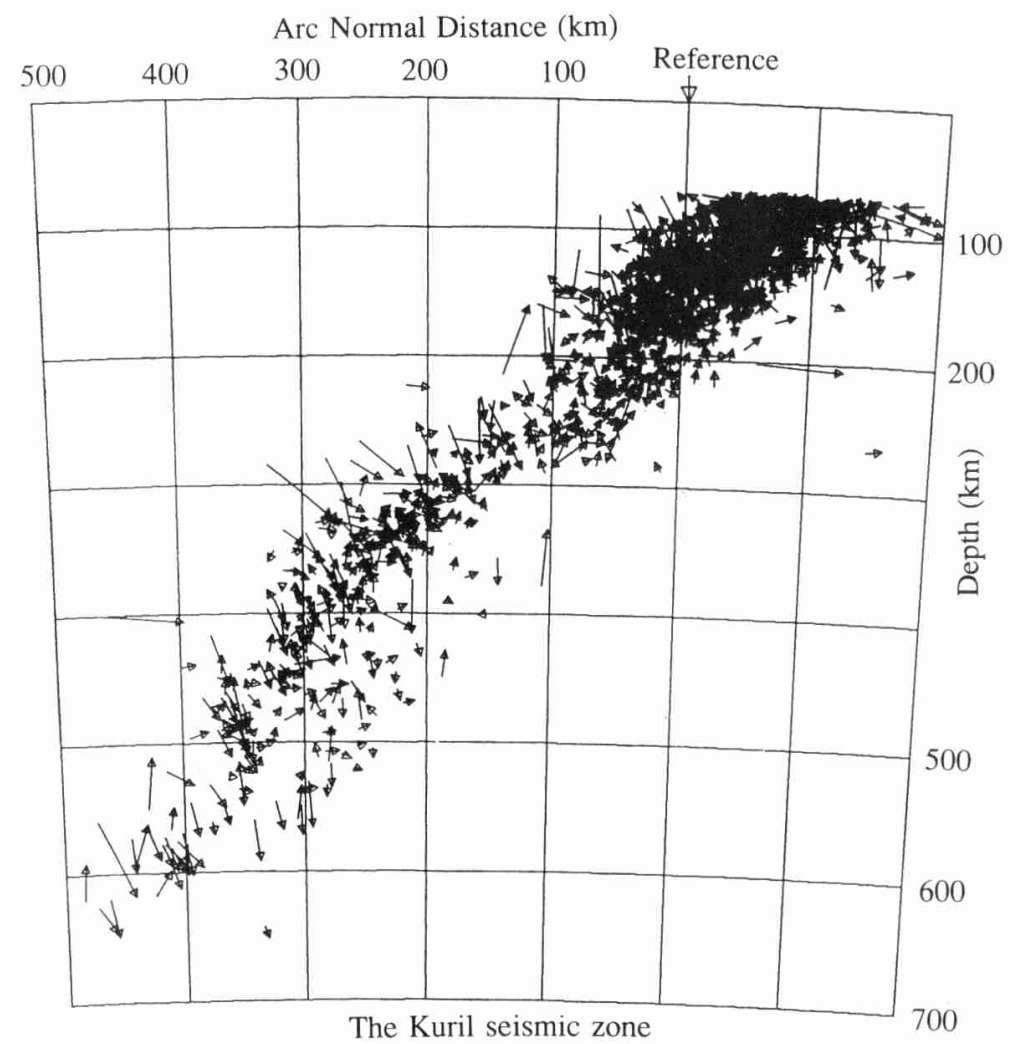

Fig. 3. Vertical cross-section illustrating the depth relocation of earthquakes in the Kuril seismic zone. The relocation arrows point from the ISC locations (tail) to the locations obtained prior to tomographic inversion (head) (see also Fig. 2). The projection to the cross-section is for a pole fitted to the volcanic arc. The epicenter region used for the construction of this section is bounded by $43.5-53^{\circ}$ in latitude and $140-160^{\circ}$ in longitude. 

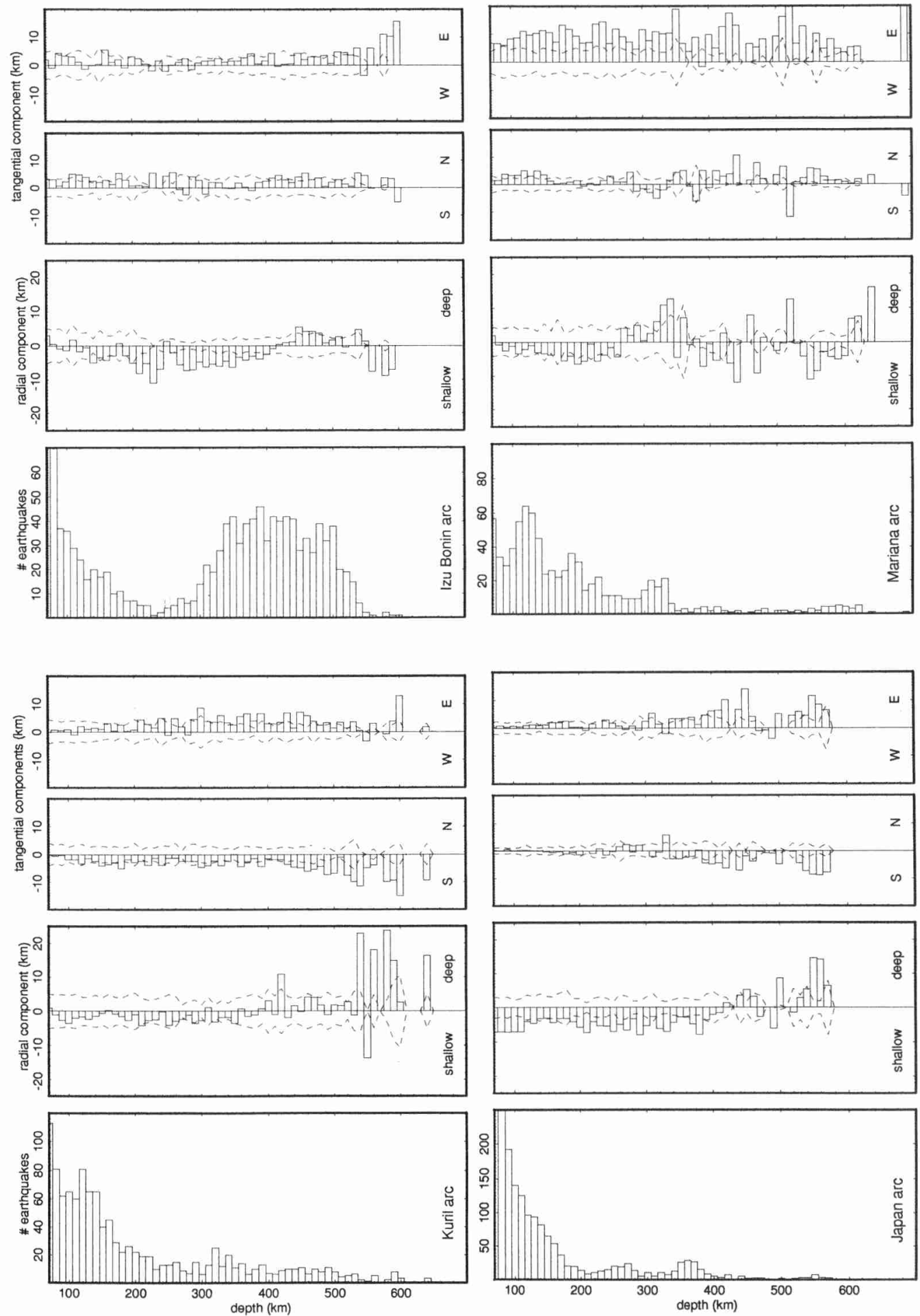

RELOGATION BEFORE INVERSION 
sophisticated techniques (see Moser et al., 1992, for a discussion). Ishida and Hasemi (1988) followed the same procedure described in this section to obtain a 3-D velocity model for the shallow mantle below southern Japan, but the explicit relocation of hypocenters was done in a subsequent computation, using the velocity model resulting from the inversion as input.

\section{Results}

\subsection{Results of relocation before inversion}

In Fig. 2 are shown epicenter relocation vectors relative to ISC determinations (the tail of the arrow) for intermediate-depth and deep earthquakes (focal depths larger than $70 \mathrm{~km}$ ) below the Kuril islands and the Sea of Okhotsk, as determined prior to inversion for 3-D mantle structure. In the present analysis we only consider hypocenter relocations with a total relocation vector smaller than $50 \mathrm{~km}$. A few relocation vectors larger than that were associated with events improperly determined by the ISC (Engdahl and Van der Hilst, 1991).

Relocation vectors for earthquakes below the back-arc region can be quite large, with the direction of relocation systematically perpendicular to the strike of the seismic zone and towards the arc. For earthquakes below the arc and seaward of the trench, epicenter relocation vectors are smaller and less systematic. These observations are in agreement with theoretical results of teleseismic mislocation (Nieman et al., 1986). In Fig. 3 we plot relocation vectors of earthquakes greater than $70 \mathrm{~km}$ in depth in a vertical crosssection. This figure is constructed by projecting earthquakes with epicenters in the geographic region with latitudes between $43.5^{\circ} \mathrm{N}$ and $53.0^{\circ} \mathrm{N}$, and longitudes between $140.0^{\circ} \mathrm{E}$ and $160.0^{\circ} \mathrm{E}$ to the section plane along arc segments around a pole at $53.814^{\circ} \mathrm{N}, 139.985^{\circ} \mathrm{E}$. The use of this pole, which is fitted to the volcanic arc, gives a good fit for earthquakes with focal depths less than 200 km (see Engdahl and Van der Hilst, 1991). Lateral plate contortion (e.g. Van der Hilst et al., 1991) has the effect of broadening the seismic zone between 200 to $700 \mathrm{~km}$ in depth. For earthquakes with focal depths exceeding $500 \mathrm{~km}$ the hypocenters are relocated systematically towards the arc (see also Fig. 2) and downwards. The relocation thus causes the deepest part of the seismic zone to be steeper than inferred from ISC hypocenters, enhancing the change in dip described and modelled by Jordan (1977) and by Creager and Jordan (1984).

For the four major subduction zones in the northwest Pacific region, we counted the seismic events in $10 \mathrm{~km}$ depth bins, and determined average spatial components of the relocation vectors (Fig. 4). The earthquake depth distribution is shown in the leftmost panels for four northwest Pacific island arcs. The other three panels display for each island arc the average relocation of focal depth (radial component), and epicenter latitude and longitude (tangential components). We also computed for each depth bin the standard deviation $\sigma$ from the average for each spatial component of relocation. In Fig. 4 we represented the variability in the relocation vectors by the dashed lines drawn at $\pm 0.5 \sigma$. The geographic coordinates used to define the four regions are (43.5$53.0^{\circ} \mathrm{N}$ and $140.0-160.0^{\circ} \mathrm{E}$ ) for the Kuril region and $\left(34.5-43.0^{\circ} \mathrm{N}\right.$ and $\left.125.0-142.0^{\circ} \mathrm{E}\right),(23.0-$ $34.5^{\circ} \mathrm{N}$ and $\left.135.0-145.0^{\circ} \mathrm{E}\right)$, and $\left(10.0-25.0^{\circ} \mathrm{N}\right.$ and $\left.140.0-155.0^{\circ} \mathrm{E}\right)$ for the Japan, Izu Bonin, and Mariana regions, respectively.

Systematic trends in depth and epicenter location prior to tomographic inversion are evident from these frequency distributions. The distribution for the Kuril arc confirms what can be in-

\footnotetext{
Fig. 4. Spatial components of the relocation vectors for earthquakes in the four major seismic zones in the northwest Pacific region. The relocation vectors are determined prior to inversion for 3-D Earth structure with iasp91 software and a combination of P-and $\mathrm{pP}$-wave travel-time residuals relative to iasp91. For each of the seismic zones the depth distribution of seismicity is given in the leftmost panel; the depth relocation (radial component) and epicenter relocation (tangential components) are presented in the other three panels. The relocations presented are averaged over $10 \mathrm{~km}$ depth bins. Dashed lines are drawn at $\pm 0.5 \sigma$, with $\sigma$ the standard deviation from the average relocation in a particular depth bin.
} 

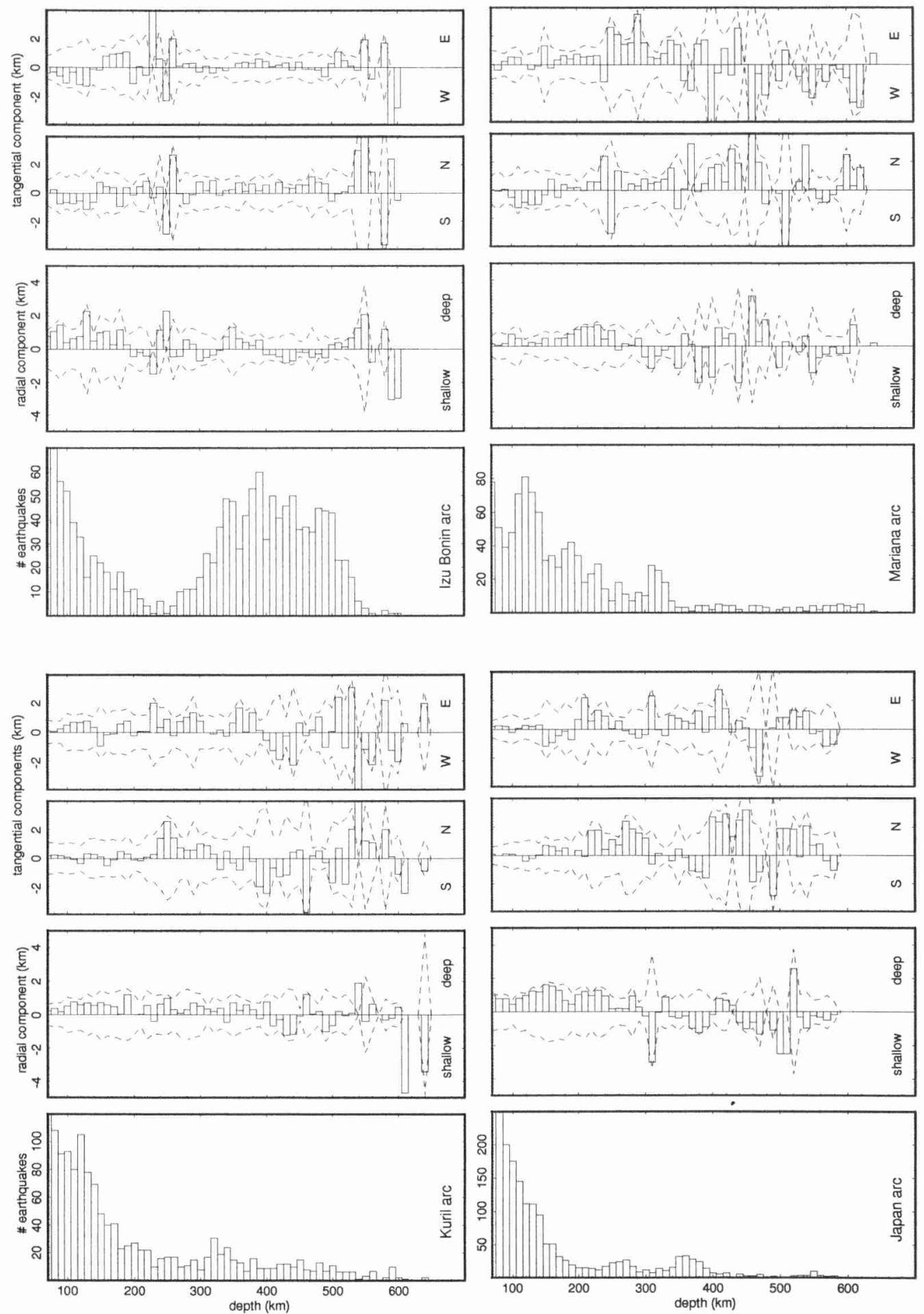

RELOCATION UPON INVERSION: P + PP DATA

Fig. 5. Spatial components of relocation vectors determined upon inversion of P- and pP-wave travel-time residuals. For explanation see the caption of Fig. 4. Note that in this figure the scale used for the size of the average relocations differs from that in Fig. 4. 
ferred visually from Figs. 2 and 3. For deeper earthquakes the average epicenter relocation in the $10 \mathrm{~km}$ depth bins is consistently towards the southeast. The standard deviation in the epicenter relocation is $5-10 \mathrm{~km}$. The significant increase of the southward component for deeper events applies, in particular, to the earthquakes located below the southern part of the Sea of Okhotsk. The depth relocation is better illustrated with the frequency distribution in Fig. 4 than with the vertical section in Fig. 3. For earthquakes down to about $400 \mathrm{~km}$ in depth, hypocenters are relocated to depths that are on average up to $5 \mathrm{~km}$ less than the corresponding ISC depths. This relocation to shallower depths is consistent with a fast slab below these intermediate-depth earthquakes (Fig. 1). For the Kuril seismic zone these depth relocations are small with respect to the standard error in the distribution. As observed in Fig. 3, the very deep earthquakes (focal depth larger than $500 \mathrm{~km}$ ) are relocated to significantly greater depths by about 20 $\mathrm{km}$.

For the earthquakes in the Japan seismic zone the epicenter relocation is also predominant towards the southeast, with larger relocations for greater focal depths: the average epicenter location is about $10 \mathrm{~km}$ for earthquakes deeper than $400 \mathrm{~km}$. The number of earthquakes below 400 $\mathrm{km}$ to which this relocation applies is small for the seismic zone below the Japan arc, but the scatter in the relocation parameters is also relatively small. Over most of the depth range, earthquakes are relocated to significantly smaller depths, but, similar to the events in Kuril zone, the deepest earthquakes are located deeper than the ISC determinations. The depth relocation for seismic events in the Izu Bonin and Mariana seismic zones differs from that described above for the Japan and Kuril zones. In contrast to the deepest events in the other seismic zones, the deepest earthquakes below the Izu Bonin arc are relocated to shallower depths. In the Mariana region the variability of the relocation vectors with focal depth is larger than in the other regions, although these variations may not be significant for focal depths less than about $400 \mathrm{~km}$. Along the Izu Bonin arc, intermediate-depth earthquakes (focal depth between 70 and $300 \mathrm{~km}$ ) are relocated to shallower depths. For earthquakes in the entire depth range, the epicenter relocation is systematically northeast and eastnortheast for the Izu Bonin and Mariana zones, respectively.

The correlation between the number of earthquakes in a particular depth bin and the average hypocenter relocation is small, apart from the large relocation vectors for the deepest events, which are fewer in number. Also the standard deviation of the mean in each $10 \mathrm{~km}$ depth bin is rather constant over the entire depth range, with the exception of the depth relocation in the Mariana seismic zone.

\subsection{Results of relocation upon tomographic inver- sion}

In Fig. 5 we show a set of frequency distributions similar to that of Fig. 4 for the three spatial components of the relocation vectors determined upon inversion of $\mathrm{P}$ and $\mathrm{pP}$ residuals for subduction zone structure. From a comparison with the corresponding distributions in Fig. 4 we infer that, compared with the relocation before inversion: (1) the average relocation computed upon inversion is much smaller (note the difference in scale!); (2) the direction of relocation is less systematic with regard to position in the slab; (3) the variations with focal depth of the relocation parameters are, in general, well within the standard deviation. In contrast to the relocation before inversion, the relocation parameters averaged in Fig. 5 (and 6) are computed for event clusters; the scatter in the parameters is mainly due to lateral variation along the strike of the seismic zones. With regard to point (1) above, we recall that we have no objective measure to weight the effect on travel time of relocation vs. Earth structure.

For intermediate-depth earthquakes in all regions, relocation upon inversion is opposite in direction to the much larger and more significant changes in focal depth achieved before inversion. The hypocenters of some of the deepest earthquakes are relocated to a slightly smaller depth.

For the relocation upon inversion, Fig. 5 re- 

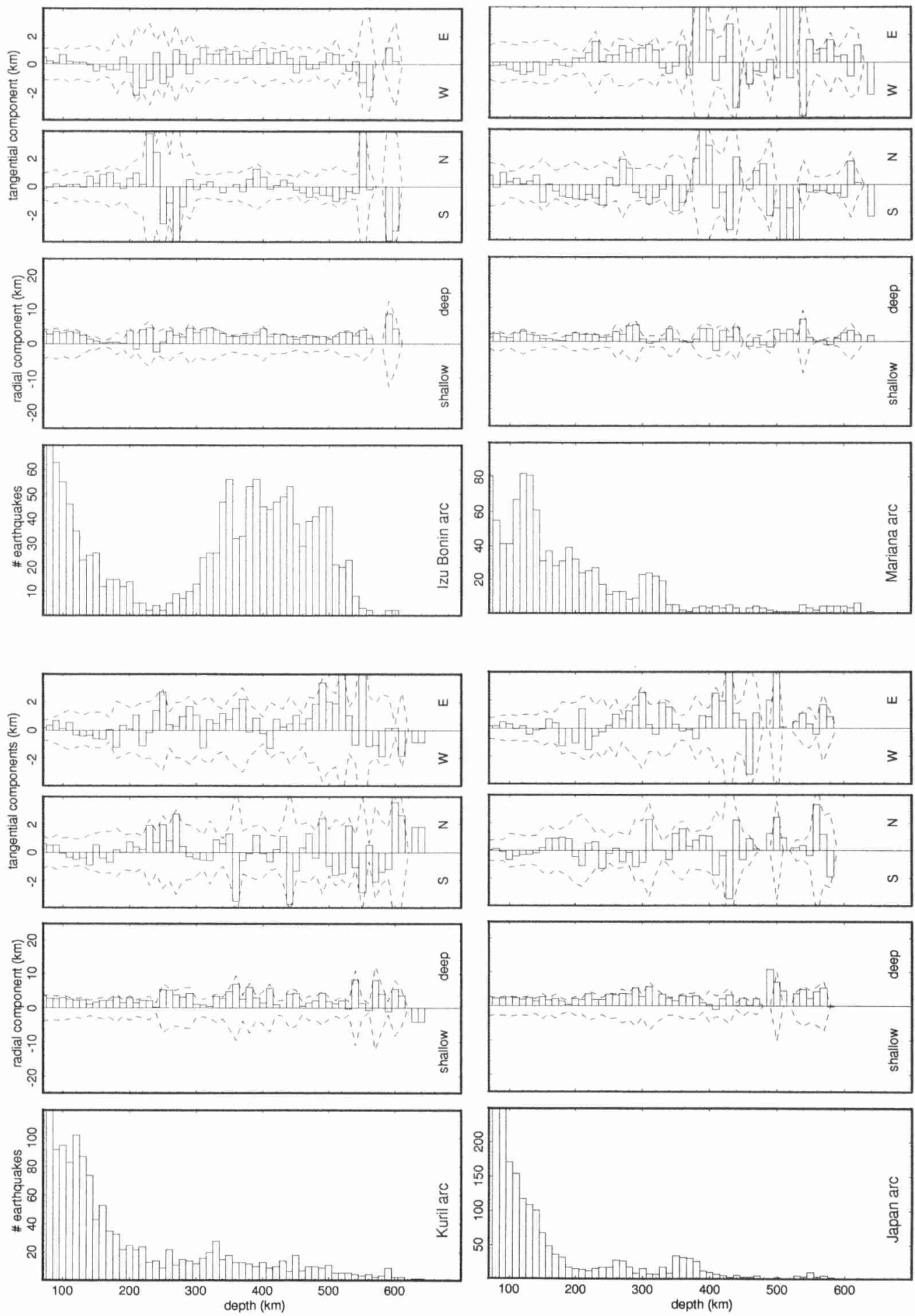

RELOCATION UPON INVERSION: P DATA ONLY

Fig. 6. Spatial components of relocation determined upon inversion of P-wave travel-time residuals only. For explanation see the caption of Fig. 4. 
veals a strong correlation between the size of the relocation vectors and the number of earthquakes in each depth bin. Compare, for example, the variation in the spatial components of relocation with the depth distribution of earthquakes in the Izu Bonin seismic zone. Also, the scatter in the relocation parameters is large and the average relocations are barely significant. Note that for depth bins with only one earthquake, $\sigma$ is meaningless and not given. The relocation parameters for individual clusters can be relatively large yet much smaller than those of individual earthquakes determined prior to inversion (Fig. 4) but they are not coherent over adjacent clusters.

In Fig. 6 we show the result of the relocation upon inversion for a case in which we used only $\mathrm{P}$ residuals in the tomographic imaging. Given the large scatter, the average relocations in epicenter are similar both in size and direction to those obtained with the combination of $\mathrm{P}$ and $\mathrm{pP}$ residuals used in the inversion. This is not surprising because $\mathrm{pP}$ data are not sensitive to small changes in epicenter location, and the inclusion of $\mathrm{pP}$ residuals would thus not influence the epicenter relocation significantly. More important for our discussion is the effect on focal depth. If only $\mathrm{P}$-wave travel-time residuals are used in the inversion, the relocation achieved prior to imaging (Fig. 4) is almost completely undone. This applies, in particular, to the relocation of intermediate-depth earthquakes to shallower depths (Figs. 1 and 4). This result is also in accord with our expectations. The 'extra' slab signal that was added to the $\mathrm{P}$ residuals upon our relocation prior to inversion will be consistent over the observations, which is why the signal was absorbed in mislocation by the ISC. Upon our least-squares inversion of the P-wave data, this common signal, which can be of the order of the magnitude of reported residuals, will be projected back into the source term. This relocation will trade off directly with the variations of seismic velocity imaged in the vicinity of the seismic zone, resulting in the underestimation of the seismic velocity contrast between slab and adjacent mantle. The depth relocation is much smaller if the $\mathrm{pP}$ residuals are included in the inversion (Fig. 5). When pP data are incorporated, the travel-time residuals will be projected primarily into perturbations to the iasp91 reference velocities instead of hypocenter mislocation. This explains why the amplitudes of the seismic velocity contrast between slab and mantle are significantly higher than previously reported when $\mathrm{P}$ and $\mathrm{pP}$ data are used in the tomographic inversion for northwest Pacific slab structure (Van der Hilst et al., 1991).

\section{Conclusions}

Our study of the northwest Pacific (Van der Hilst et al., 1991, 1992; Engdahl and Van der Hilst, 1991) is the first in which iasp91, the new radially stratified model for $\mathrm{P}$ - and $\mathrm{S}$-wave velocities, is used to relocate earthquake hypocenters routinely, identify seismic phases, and subsequently perform seismic imaging. We reported earlier that after reprocessing of ISC hypocenters and phase data with the iasp91 travel-time tables, the variance of $\mathrm{P}$ data is $17 \%$ less than the variance of reported ISC P-wave travel-time residuals. This is of the same order of magnitude as the variance reduction typically obtained upon tomographic inversion. We therefore conclude that the reprocessing of ISC hypocenters and phase data with iasp91 software was very successful for the northwest Pacific.

Our two-step relocation of ISC hypocenters in a more appropriate spherically symmetric reference model results in better starting locations for the subsequent linearized tomographic inversion. In contrast, the relocation parameters determined upon inversion are effectively 'residuals' of the tomographic inversion for 3-D Earth structure. Thus, the relocation prior to inversion has a fundamentally different objective than the hypocenter relocation upon tomographic inversion. There is no objective measure to weight upon inversion the effect on travel-time residuals of source relocation versus Earth structure. By incorporating $\mathrm{pP}$ data in the inversion, however, earthquake focal depth can be constrained in an educated way.

For intermediate- and deep-focus earthquakes (focal depth exceeding $70 \mathrm{~km}$ ) in the seismic zones below northwest Pacific island arcs, the 
relocation before inversion yields relocation vectors with lengths of the order of $10 \mathrm{~km}$ and directions which are systematic with regard to the position of the earthquakes in the subduction zone. The computed relocations are significant with respect to the estimated standard deviation in the relocation parameters. Hypocenter relocations of this order of magnitude are substantial with respect to the variations in seismic velocity that are imaged; for seismic velocities typical of the upper mantle, a change in focal depth of 10 $\mathrm{km}$ is equivalent to a difference in teleseismic travel time of $0.5-1.0 \mathrm{~s}$ and a velocity anomaly of several per cent. The spatial components of the relocation vectors determined upon inversion are up to an order of magnitude smaller, do not reveal a correlation with location in the seismic zone, and do not generally exceed the noise level.

Without the relocation prior to inversion, the bias in ISC hypocenters would have been mapped directly into the solution of the linearized tomographic inversion. It was essential to incorporate $\mathrm{pP}$ data in the relocation to remove the depth bias prior to inversion, to retrieve slab signal that might have been absorbed in mislocation, and to constrain the focal depth upon seismic inversion. Clearly, non-linear inversion schemes, in which source locations can be updated iteratively, will not be efficient in removing the depth bias or in retrieving lost slab signal unless other seismic phases that contain information about the depth bias, like the depth phase $\mathrm{pP}$, are used.

\section{Acknowledgments}

We thank Wim Spakman for making available his software, which was, after modifications necessary for our specific purposes, used for the tomographic inversions. Suggestions by David Gubbins improved the manuscript. RvdH was financially supported by NERC (QR3/7488).

\section{References}

Adams, R.D., Hughes, A.A. and McGregor, D.M., 1982. Analysis procedures at the International Seismological Centre. Phys. Earth Planet. Inter., 30: 85-93.
Aki, K. and Richards, P.G., 1980. Quantitative Seismology: Theory and Methods. W.H. Freeman, San Fransisco, CA, $932 \mathrm{pp}$.

Billington, S., 1980. The morphology and tectonics of the subducted lithosphere in the Tonga-Fiji-Kermadec region from seismicity and focal mechanism solutions. Ph. D. Thesis, Cornell University, Ithaca, NY, $220 \mathrm{pp}$.

Bolt, B.A., 1960. The revision of earthquake epicenters, focal depths, and origin times using a high-speed computer. Geophys. J. R. Astron. Soc., 3: 433-440.

Buland, R., 1976. The mechanics of locating earthquakes. Bull. Seismol. Soc. Am., 66: 173-187.

Buland, R., 1986. Uniform reduction error analysis. Bull. Seismol. Soc. Am., 76: 217-230.

Buland, R. and Chapman, C., 1983. The computation of seismic travel times. Bull. Seismol. Soc. Am., 73: 12711302.

Burbach, G.V. and Frohlich, C., 1986. Intermediate and deep seismicity and lateral structure of subducted lithosphere in the circum-Pacific region. J. Geophys. Res., 24: 833-874.

Burnley, P.C. and Green, II, H.W., 1991. Faulting associated with the olivine to spinel transformation in $\mathrm{Mg}_{2} \mathrm{GeO}_{4}$ and its implications for deep-focus earthquakes. J. Geophys. Res., 96: 425-443.

Chiu. J.-M., Isacks B.L. and Cardwell, R.K., 1991. 3-D configuration of subducted lithosphere in the western Pacific. Geophys. J. Int., 106: 99-112.

Creager, K.C. and Jordan, T.H., 1984. Slab penetration into the lower mantle. J. Geophys. Res., 89: 3031-3049.

Creager, K.C. and Jordan, T.H., 1986. Slab penetration into the lower mantle beneath the Mariana and other island arcs of the northwest Pacific. J. Geophys. Res., 91: 3573 3589.

Dziewonski, A.M. and Anderson, D.L., 1983. Travel-times and station corrections for $\mathrm{P}$ waves at teleseismic distances. J. Geophys. Res., 88: 3295-3314.

Engdahl, E.R., 1973. Relocation of intermediate depth earthquakes in the central Aleutians by seismic ray tracing. Nature, 245: 23-25.

Engdahl, E.R. and Billington, S., 1986. Focal depth determination of central Aleutian earthquakes. Bull. Seismol. Soc. Am., 76: 77-93.

Engdahl, E.R. and Gubbins, D., 1987. Simultaneous traveltime inversion for earthquake location and subduction zone structure in the Central Aleutian Islands. J. Geophys. Res., 92: 13855-13862.

Engdahl, E.R. and Scholz, C.H., 1977. A double Benioff zone beneath the central Aleutians: an unbending of the lithosphere. Geophys. Res. Lett., 4: 473-476.

Engdahl, E.R. and van der Hilst, R.D., 1991. Reprocessing of ISC phase data for northwest Pacific earthquakes. EOS Trans. Am. Geophys. Union, 72: 1991 (abstract).

Engdahl, E.R., Sleep, N.H. and Lin, M.-T., 1977. Plate effects in North Pacific subduction zones. Tectonophysics, 37: 95-116.

Engdahl, E.R., Dewey, J.W. and Fujita, K., 1982. Earthquake location in island arcs. Phys. Earth Planet. Inter., 30: $145-156$. 
Fischer, K.M., Creager, K.C. and Jordan, T.H., 1991. Mapping the Tonga slab. J. Geophys. Res., 96: 14403-14427.

Frohlich, C., 1989. The nature of deep focus earthquakes. Annu. Rev. Earth Planet. Sci., 17: 227-254.

Fukao, Y., Obayashi, M., Inoue, H. and Nenbai, M., 1992. Subducting slabs stagnant in the mantle transition zone. J. Geophys. Res., 97: 4809-4822.

Hasegawa, A., Umino, N. and Takagi, A., 1978a. Doubleplaned structure of the deep seismic zone in the northern Japan arc. Tectonophysics, 47: 43-58.

Hasegawa, A., Umino, N. and Takagi, A., 1978b, Doubleplaned deep seismic zone and upper mantle structure in the northeastern Japan arc. Geophys. J.R. Astron. Soc., 54: $281-296$

Hasegawa, A., Zhao, D., Yamamoto, A. and Horiuci, S., 1991. Deep structure of the northeastern Japan arc and its relationship to seismic and volcanic activity. Nature, 352: $683-689$.

Helffrich, G. and Brodholt, J., 1991. Relationship of deep seismicity to the thermal structure of subducted lithosphere. Nature, 353: 252-253.

Hirahara, K. and Mikumo, T., 1980. Three-dimensional seismic structure of subducting lithospheric plates under the Japan islands. Phys. Earth Planet. Inter., 21: 109-119.

Iidaka, T. and Suetsugu, D., 1990. Effects of the distortion of the olivine-spinel phase boundary in the subducting slab on body wave amplitudes. EOS Trans. Am. Geophys. Union, 71: 898 (abstract).

Iidaka, T. and Suetsugu, D., 1992. Seismological evidence for metastable olivine in a subducting slab. Nature, 356: 593 595.

Inoue, H., Fukao, Y., Tanabe, K. and Ogata, Y., 1990. Whole mantle P-wave travel-time tomography. Phys. Earth Planet. Inter., 59: 294-328.

Isacks, B.L. and Barazangi, M., 1977. Geometry of Benioff zones: lateral segmentation and downward bending of subducted lithosphere. In: M. Talwani, and W.C. Pitman III (Editors), Island Arcs, Deep Sea Trenches and BackArc Basins. Maurice Ewing Ser., Vol. 1, American Geophysical Union, Washington, DC, pp. 99-114.

Ishida, M. and Hasemi, A.H., 1988. Three-dimensional fine velocity structure and hypocentral distribution of earthquakes beneath the Kanto-Tokai district, Japan. J. Geophys. Res., 93: 2076-2094.

Jeffreys, H., 1939. Theory of Probability. Clarendon Press. Oxford

Jeffreys, H. and Bullen, K.E., 1967. Seismological Tables, British Association for the Advancement of Science, London.

Jordan, T.H., 1977. Lithospheric slab penetration into the lower mantle beneath the Sea of Okhotsk. J. Geophys. Res., 43: 473-496.

Kamiya, S., Miyatake, T. and Hirahara, K., 1988. How deep can we see the high velocity anomalies beneath the Japan islands? Geophys. Res. Lett., 15: 828-831.

Kennett, B.L.N., 1991. IASPEI 1991: Seismological Tables.
Research School of Earth Sciences, Australian National University, Canberra. A.C.T., 167 pp.

Kennett, B.L.N. and Engdahl, E.R., 1991. Travel times for global earthquake location and phase identification. Geophys. J. Int., 105: 429-466.

Kirby, S.H., Durham, W.B. and Stem, L.A., 1991. Mantle phase changes and deep-earthquake faulting in subducted lithosphere. Science, 252: 216-225.

Moser, T.J., Van Eck, T. and Nolet, G., 1992. Hypocenter determination in strongly heterogeneous Earth models using the shortest path method. J. Geophys. Res., 97: 6563-6572

Nakanishi, I., 1985. Three-dimensional structure beneath the Hokkaido-Tohuko region as derived from a tomographic inversion of P-arrival times. J. Phys. Earth, 33: 241-256.

Nieman, T.L., Fujita, K. and Rogers, Jr., W.J., 1986. Teleseismic mislocation of earthquakes in island arcs - theoretical results. J. Phys. Earth, 34: 43-70.

Nolet, G., 1985. Solving or resolving inadequate and noisy tomographic systems. J. Comput. Phys., 61: 463-468.

Paige, C.C. and Saunders, M.A., 1982. LSQR: an algorithm for sparse linear equations and sparse least squares. ACM Trans. Math. Soft., 8: 43-71 and 195-209.

Spakman, W., 1988. Upper mantle delay time tomography with an application to the collision zone of the Eurasian, African and Arabian Plates. Ph. D. Thesis, University of Utrecht, $200 \mathrm{pp}$.

Spakman, W. and Nolet, G., 1988. Imaging algorithms, accuracy and resolution in delay time tomography. In: N.J. Vlaar et al. (Editors), Mathematical Geophysics: a Survey of Recent Developments in Seismology and Geodynamics. Reidel, Dordrecht, pp. 155-188.

Spakman, W., Stein, S., van der Hilst, R.D. and Wortel, R., 1989. Resolution experiments for NW Pacific subduction zone tomography. Geophys. Res. Lett., 16: 1097-1101.

Spencer, C. and Gubbins, D., 1980. Travel-time inversion for simultaneous earthquake location and velocity structure determination in laterally varying media. Geophys. J. R. Astron. Soc., 63: 95-116.

Suetsugu, D., 1989. Lower mantle high-velocity zone beneath the Kurils as inferred from P-wave travel time and amplitude data. J. Phys. Earth, 37: 265-295.

Van der Hilst, R.D. and Engdahl, E.R., 1991. On ISC PP and $\mathrm{pP}$ data and their use in delay-time tomography of the Caribbean region. Geophys. J. Int., 106: 169-188.

Van der Hilst, R.D., Engdahl, E.R., Spakman, W. and Nolet, G., 1991. Tomographic imaging of subducted lithosphere below northwest Pacific island arcs. Nature, 353: 37-43.

Van der Hilst, R.D., Engdahl, E.R. and Spakman, W., 1992. Aspherical mantle structure below the northwest Pacific region, II tomographic inversion of $\mathrm{P}$ and $\mathrm{pP}$ data. Geophys. J. Int. (in press).

Zhou, H.W. and Clayton, R.W., 1990. P and S wave travel-time inversions for subducting slab under the island arcs of the northwest Pacific. J. Geophys. Res., 95: 6829-6854. 